\title{
Crystal Structures and Electronic Properties of Haloform-Intercalated $\mathbf{C}_{60}$
}

\author{
René Windiks, Andreas Bill and Bernard Delley \\ Paul Scherrer Institut, Condensed Matter Theory Group, CH-5232 Villigen PSI, Switzerland \\ V. Z. Kresin \\ University of California, Lawrence Berkeley Laboratory, Berkeley CA 94720, USA
}

(Dated: October 25, 2018)

\begin{abstract}
Using density functional methods we calculated structural and electronic properties of bulk chloroform and bromoform intercalated $\mathrm{C}_{60}, \mathrm{C}_{60} \cdot 2 \mathrm{CHX}_{3}(\mathrm{X}=\mathrm{Cl}, \mathrm{Br})$. Both compounds are narrow band insulator materials with a gap between valence and conduction bands larger than $1 \mathrm{eV}$. The calculated widths of the valence and conduction bands are $0.4-0.6 \mathrm{eV}$ and $0.3-0.4 \mathrm{eV}$, respectively. The orbitals of the haloform molecules overlap with the $\pi$ orbitals of the fullerene molecules and the $p$-type orbitals of halogen atoms significantly contribute to the valence and conduction bands of $\mathrm{C}_{60} \cdot 2 \mathrm{CHX}_{3}$. Charging with electrons and holes turns the systems to metals. Contrary to expectation, 10 to $20 \%$ of the charge is on the haloform molecules and is thus not completely localized on the fullerene molecules. Calculations on different crystal structures of $\mathrm{C}_{60} \cdot 2 \mathrm{CHCl}_{3}$ and $\mathrm{C}_{60} \cdot 2 \mathrm{CHBr}_{3}$ revealed that the density of states at the Fermi energy are sensitive to the orientation of the haloform and $\mathrm{C}_{60}$ molecules. At a charging of three holes, which corresponds to the superconducting phase of pure $\mathrm{C}_{60}$ and $\mathrm{C}_{60} \cdot 2 \mathrm{CHX}_{3}$, the calculated density of states (DOS) at the Fermi energy increases in the sequence $\operatorname{DOS}\left(\mathrm{C}_{60}\right)<\operatorname{DOS}\left(\mathrm{C}_{60} \cdot 2 \mathrm{CHCl}_{3}\right)<\operatorname{DOS}\left(\mathrm{C}_{60} \cdot 2 \mathrm{CHBr}_{3}\right)$.
\end{abstract}

\section{INTRODUCTION}

This paper is concerned with structural and electronic properties of solid $\mathrm{C}_{60}$ intercalated with haloform molecules, $\mathrm{CHX}_{3}(\mathrm{X}=\mathrm{Cl}, \mathrm{Br})$. These compounds have been studied recently by $\mathrm{X}$-ray diffraction [1, 2, 3] and solid-state nuclear magnetic resonance (NMR) spectroscopy [2, 印.

These kind of fullerene based materials have attracted a lot of attention because of their unusual conducting and superconducting properties. Solid $\mathrm{C}_{60}$ is insulating but can be made conducting and even superconducting upon intercalation of alkali atoms (e.g. K, Rb) between the fullerene molecules (see the reviews [5, 6, 可). The alkali atoms transfer their valence electrons into the conduction bands of the $\mathrm{C}_{60}$ subsystem and the materials become metallic.

A noticeable enhancement of the superconducting critical temperature, $T_{c}$, of $\mathrm{C}_{60}$ was expected when electrons are removed (hole doping) because of the larger density of states of the valence bands. Doping of $\sim 3$ holes per $\mathrm{C}_{60}$ molecule and corresponding metalization was achieved with the use of field-effect doping technique and has resulted in $T_{c}=52 \mathrm{~K}$ [8]. Such doping has also been realized recently [9, 10]. The intercalation of $\mathrm{C}_{60}$ with haloform molecules has led to an further increase of the critical temperature [11]. Such an enhancement of $T_{c}$ upon intercalation of molecules into a superconductor has been already observed earlier [12] and was discussed theoretically [13]. In this work we focus on the normal properties of haloform intercalated $\mathrm{C}_{60}$.

$\mathrm{X}$-ray powder diffraction measurements at various temperatures [1], 3] have shown that above $\sim 200 \mathrm{~K}$ the crystal structure of haloform intercalated $\mathrm{C}_{60}$ is hexagonal and transforms to a triclinic structure below $T \sim 150 \mathrm{~K}$. The stoichiometric composition of these materials is $\mathrm{C}_{60} \cdot 2 \mathrm{CHX}_{3}$

*Electronic address: rene.windiks@psi.ch
( $\mathrm{X}=\mathrm{Cl}, \mathrm{Br}$ ). Solid state NMR measurements on $\mathrm{C}_{60} \cdot 2 \mathrm{CHBr}_{3}$ have shown that above $193 \mathrm{~K}$ the $\mathrm{C}_{60}$ molecules rotate isotropically [ [] , similar to that found in pure face-centered cubic (fcc) $\mathrm{C}_{60}$. Whereas below this temperature a rotation barrier of $6 \mathrm{~kJ} \cdot \mathrm{mol}^{-1}$ was evaluated. Also the bromoform molecules are found to be motionally active down to $218 \mathrm{~K}$ 沟].

Dinnebier et al. [3] calculated the electronic structure of these materials using a two-dimensional periodic tightbinding formalism where only one specific lattice plane was considered. They omitted the haloform molecules completely and took only the valence electrons of the five-fold degenerate $h_{u}$ molecular orbital (MO) of each $\mathrm{C}_{60}$ explicitely into account. The main conclusion of their calculations is that the electronic density of states (DOS) at the Fermi energy for $\sim 3$ holes per $\mathrm{C}_{60}$ molecule satisfies following sequence: $\operatorname{DOS}\left(\mathrm{C}_{60} \cdot 2 \mathrm{CHBr}_{3}\right) \approx \operatorname{DOS}\left(\mathrm{C}_{60} \cdot 2 \mathrm{CHCl}_{3}\right)<\operatorname{DOS}\left(\mathrm{C}_{60}\right)$. Hence, the observed enhancement of $T_{c}$ cannot simply be explained by an increase of the DOS at the Fermi energy when $\mathrm{C}_{60}$ is intercalated with haloform molecules and $\mathrm{CHCl}_{3}$ is replaced by $\mathrm{CHBr}_{3}$ (vide supra). Given these observations and results, it is of interest to study the electronic properties of these materials in more detail.

We have performed all-electron density functional (DF) calculations on several crystal structures of bulk $\mathrm{C}_{60} \cdot 2 \mathrm{CHX}_{3}$ $(\mathrm{X}=\mathrm{Cl}, \mathrm{Br})$ to predict their electronic structures and to examine the effect of introduced charge carriers (doping with electrons as well as with holes). Employed are methods that rely on the generalized gradient approximation (GGA) and the spinunrestricted Kohn-Sham approach. Different charge doping levels are simulated simply by removing or adding electrons from the systems. Unlike previous work [3] our DF calculations include all electrons of the system into the quantum treatment and the haloform molecules are taken into account explicitly. Particular attention is paid to the interaction of the haloform molecules with the electronic structure of the $\mathrm{C}_{60}$ subsystem. DF calculations have also been performed on an fcc and on a hypothetical hexagonal lattice of $\mathrm{C}_{60}$ molecules. 
TABLE I: Crystal structures of pure $\mathrm{C}_{60}$ and $\mathrm{C}_{60} \cdot 2 \mathrm{CHX}_{3}$ $(\mathrm{X}=\mathrm{Cl}, \mathrm{Br}$ ) reported in the literature and used in this work (unit cell lengths in $\AA$, angles in degrees). Note, for $\mathrm{C}_{60}$ the lattice parameters of the primitive cell is given.

\begin{tabular}{|c|c|c|}
\hline & pure $\mathrm{C}_{60}$ & $\mathrm{C}_{60} \cdot 2 \mathrm{CHX}_{3}(\mathrm{X}=\mathrm{Cl}, \mathrm{Br})$ \\
\hline temp. range $[\mathrm{K}]$ & 170 & $\geq 200 \quad \leq 150$ \\
\hline Bravais lattice & fcc & hexagonal \\
\hline Space groups & $\mathrm{Fm} \overline{3}$ & $\mathrm{P} \overline{3}, \mathrm{P} \overline{1}, \mathrm{P} 1$ \\
\hline acronym & & $\mathbf{H T}^{\mathbf{a})}$ \\
\hline Ref. & 14 & [1] \\
\hline
\end{tabular}

lattice parameters

\begin{tabular}{|c|c|c|c|c|c|}
\hline & & $\mathrm{X}=\mathrm{Cl}$ & $\mathrm{X}=\mathrm{Br}$ & $\mathrm{X}=\mathrm{Cl}$ & $\mathrm{X}=\mathrm{Br}$ \\
\hline$a$ & 9.949 & 10.08 & 10.212 & 9.8361 & 9.8982 \\
\hline$b$ & 9.949 & 10.08 & 10.212 & 10.0906 & 10.3386 \\
\hline$c$ & 9.949 & 10.11 & 10.209 & 9.8179 & 9.8993 \\
\hline$\alpha$ & 60.0 & 60.0 & 60.0 & 101.363 & 100.951 \\
\hline$\beta$ & 60.0 & 60.0 & 60.0 & 116.457 & 115.920 \\
\hline$\gamma$ & 60.0 & 120.0 & 120.0 & 79.783 & 78.202 \\
\hline
\end{tabular}

a) High temperature structure. ${ }^{\text {b) }}$ Low temperature structure.

The latter system is formed by artificially removing the haloform molecules from $\mathrm{C}_{60} \cdot 2 \mathrm{CHX}_{3}$. These calculations allow to examine changes in the electronic structure of the $\mathrm{C}_{60}$ subsystem (i) upon intercalation and (ii) due to electronic contributions of the haloform molecules separately. Note, that all structures and electronic properties are obtained in the absence of an applied electric field.

The structure of the article is as follows: Sec. III summarizes the experimental determination of the crystal structure of $\mathrm{C}_{60} \cdot 2 \mathrm{CHX}_{3}(\mathrm{X}=\mathrm{Cl}, \mathrm{Br}) \mathrm{Sec}$. IIII gives details about the computational method. In Sec. IV A and Sec. IV B we discuss the calculated crystal and electronic structures of the un-doped systems, respectively. Sec IV then discusses the changes of the electronic structure due to hole- and electron-doping of $\mathrm{C}_{60} \cdot 2 \mathrm{CHX}_{3}$. Finally, a concluding discussion is found in Sec. V.

\section{CRYSTAL STRUCTURES FROM X-RAY DIFFRACTION MEASUREMENTS}

The first crystal structures of $\mathrm{CHCl}_{3}$ - and $\mathrm{CHBr}_{3}$ - intercalated $\mathrm{C}_{60}$ reported in the literature were published by Jansen and Waidmann [1]. An X-ray powder diffraction analysis at room temperature yielded for both compounds a primitive hexagonal lattice and an average symmetry of P6/mmm. However, due to orientational disorder of the molecules the atomic coordinates could not be resolved. Throughout this paper this structure is labeled with HT (high temperature) and the observed lattice parameters are summarized in Table 1

Collins et al. examined the structure of $\mathrm{C}_{60} \cdot 2 \mathrm{CHBr}_{3}$ at room temperature using $\mathrm{X}$-ray powder diffraction as well and found a hexagonal lattice with unit cell parameters consistent with those for the HT structure of Table in. They calculated the atomic positions using molecular modeling techniques by placing a $\mathrm{C}_{60}$ molecule at the origin of the hexagonal unit cell and inserting the $\mathrm{CHBr}_{3}$ molecules into the trigonal prismatic voids at $(1 / 3,2 / 3,1 / 2)$ and $(2 / 3,1 / 3,1 / 2)$ [Fig. 1 1 (b)]. Based on the modeled crystal structure they calculated an X-ray diffraction pattern almost identical to the observed one. The crystal structures can be considered as a sequence of alternating layers of $\mathrm{C}_{60}$ and haloform molecules. As an example, Fig. 11(d) shows the layer structure of $\mathrm{C}_{60} \cdot 2 \mathrm{CHCl}_{3}$.

Very recently, Dinnebier et al. [3] performed high resolution X-ray powder diffraction analyses at various temperatures and determined the crystal lattices of different phases of $\mathrm{C}_{60} \cdot 2 \mathrm{CHX}_{3}(\mathrm{X}=\mathrm{Cl}, \mathrm{Br})$. In agreement with Jansen and Waidmann and Collins et al., the room temperature crystal lattice obtained is hexagonal and has $\mathrm{P} 6 / \mathrm{mmm}$ space group symmetry. At $T \approx 200 \mathrm{~K}$ the haloform intercalated fullerenes undergo a first-order phase transition towards a monoclinic phase of $\mathrm{C} 2 / \mathrm{m}$ symmetry which has the double volume of the room temperature phase. The alternating layers of haloform and $\mathrm{C}_{60}$ molecules are shifted with respect to each other such that the molecules are displaced from their equilibrium positions in the room temperature phase. Below $\sim 150 \mathrm{~K}$ a second first-order phase transition occurs and the crystal structures of

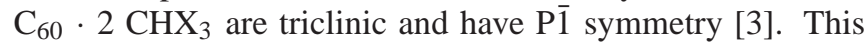
low temperature (LT) phase has similar cell dimensions as the hexagonal room temperature structure (Table I). Throughout this paper this structure is labeled with LT.

A comparison of the hexagonal unit cells of $\mathrm{C}_{60} \cdot 2 \mathrm{CHX}_{3}$ $(\mathrm{X}=\mathrm{Cl}, \mathrm{Br})$ [Fig. 11(a) and 11(b)] with the primitive unit cell of pure fcc $\mathrm{C}_{60}$ [Fig. 11(c)] emphasizes the structural changes caused by the intercalation with haloform molecules. The cubic closed-packed (ccp) lattice of $\mathrm{C}_{60}$ molecules transforms to a hexagonal close-packed lattice of $\mathrm{C}_{60}$ molecules. As a result of the intercalation the length of the primitive cell is increased by 1 to $4 \%$.

\section{COMPUTATIONAL METHOD}

All calculations are performed with the $\mathrm{DMol}^{3}$ approach 115, 16. The calculations make use of the gradient corrected density functional of Becke [17] for the exchange contribution, combined with the Perdew Wang 1991 functional [18] for the correlation contribution. All electrons are described explicitely with a double numeric basis set augmented with polarization functions (DNP): $2 \mathrm{~s} 1 \mathrm{p}$ for $\mathrm{H}, 3 \mathrm{~s} 2 \mathrm{p} 1 \mathrm{~d}$ for $\mathrm{C}$, $4 \mathrm{~s} 4 \mathrm{p} 2 \mathrm{~d}$ for $\mathrm{Cl}$ and $5 \mathrm{~s} 4 \mathrm{~s} 2 \mathrm{~d}$ for $\mathrm{Br}$. The cutoff radius to generate the atomic basis functions is set to $7.0 \mathrm{bohr}(1 \mathrm{bohr}=$ $\left.5.29177 \times 10^{-11} \mathrm{~m}\right)$. The electron densities and the energies are calculated self consistently, latter within an accuracy of $10^{-5}$ hartree $\left(1\right.$ hartree $\left.=2625.5 \mathrm{~kJ} \cdot \mathrm{mol}^{-1}\right)$. The numerical integration is performed on medium sized meshes. For the Brillouin zone integration irreducible $k$ vector meshes of different sizes are used [16]. Reliable energies and atomic positions are obtained with a $k$ vector mesh of $\left(n_{x}, n_{y}, n_{z}\right)=(4,4,2)$, where $n_{i}$ denotes the increments along each of the primitive reciprocal lattice vectors, $G_{i}$ (Fig. 2) [16]. This $k$ vector mesh amounts to 20 symmetry-inequivalent sampling points. The calculations of the DOS required a finer $k$ vector mesh of $\left(n_{x}, n_{y}, n_{z}\right)=(8,8,4)$, i.e. 132 irreducible $k$ points. Calcula- 

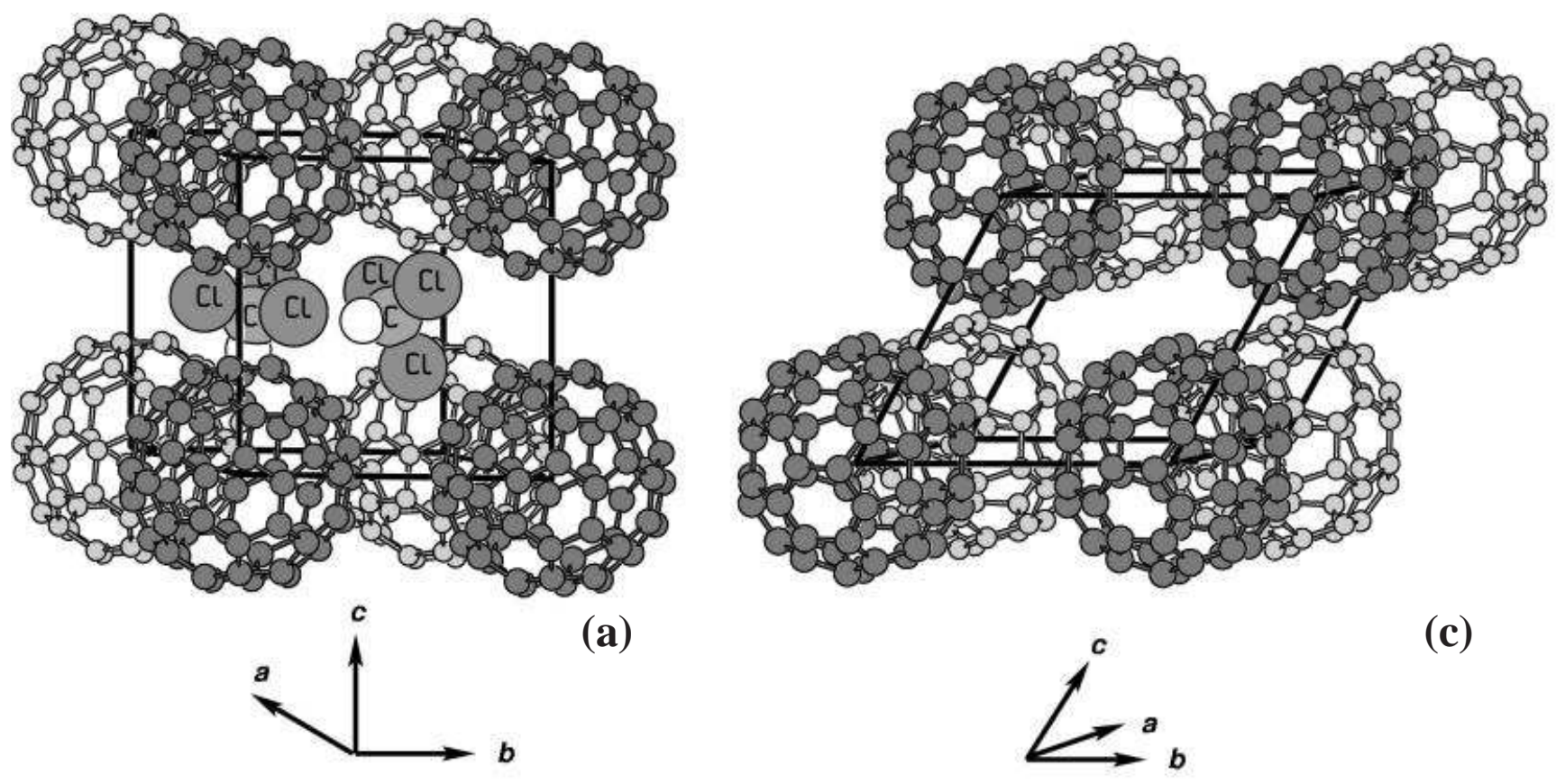

(c)
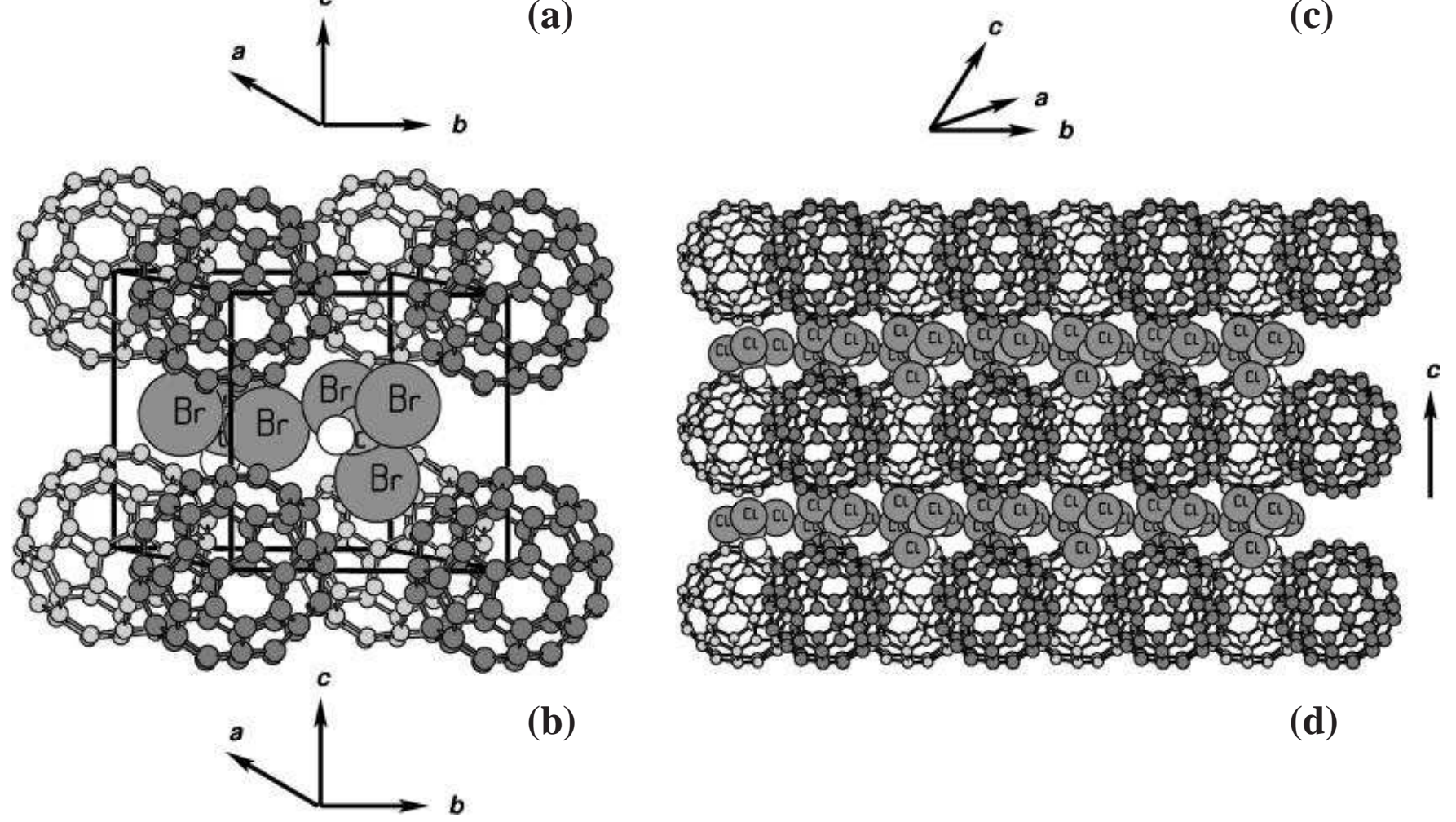

(d)

FIG. 1: Calculated configurations of (a) $\mathrm{CHCl}_{3}$ and (b) $\mathrm{CHBr}_{3}$ molecules intercalated in hexagonal lattices of $\mathrm{C}_{6}$ molecules. Both crystal structures have P1 symmetry and are based on the $\mathrm{X}$-ray powder diffraction analysis of Jansen and Waidmann [1]. (c) The molecules in pure $\mathrm{C}_{60}$ form an fcc lattice and the crystal structure has $\mathrm{Fm} \overline{3}$ symmetry. Depicted is the primitive unit cell of fcc $\mathrm{C}_{60}$. (d) The structures of hex. $\mathrm{C}_{60} \cdot 2 \mathrm{CHCl}_{3}$ and hex. $\mathrm{C}_{60} \cdot 2 \mathrm{CHBr}_{3}$ can be considered as a sequence of alternating layers of $\mathrm{C}_{60}$ molecules and haloform molecules perpendicular to the $c$ vector.

tions on $\mathrm{fcc} \mathrm{C}_{60}$ on the other hand, require only 35 symmetryunique sampling points, $\left(n_{x}, n_{y}, n_{z}\right)=(8,8,8)$. Using the selfconsistent electronic densities the electronic band structures of fcc $\mathrm{C}_{60}$ and $\mathrm{C}_{60} \cdot 2 \mathrm{CHX}_{3}(\mathrm{X}=\mathrm{Cl}, \mathrm{Br})$ are calculated at 59 and 153 reciprocal lattice vectors, respectively, at the surface of the irreducible wedge of the appropriate Brillouin zones.

Doping with holes (electrons) is simulated by simply re- moving (adding) an appropriate number electrons from the unit cell. For instance, to simulate a doping of three holes per $\mathrm{C}_{60}$ molecule, three electrons are removed and the total charge of the unit cell is denoted $Q=+3$. The resulting positive or negative charge of the system is compensated by a background counter charge (jellium approach). Considered are doping levels of $Q=0, Q= \pm 1$ and $Q= \pm 3$. The charging procedure 
forms systems with open electron shells. Therefore, all calculations on the charged systems are performed within the unrestricted Kohn-Sham formalism to account for possible spin polarization effects.

The crystal structures introduced in the next section for which the electronic properties are determined, are optimized by keeping the cell parameters fixed and allowing the atoms to move. This concerns neutral as well as charged systems. The atomic positions are optimized employing delocalized internal coordinates [19]. The convergence criteria of the optimization procedures are $10^{-5}$ hartree for the energy, $3 \times 10^{-4}$ hartree/bohr for the maximum energy gradient and $3 \times 10^{-3}$ bohr for the maximum atomic displacement.

\section{RESULTS AND DISCUSSION}

\section{A. Optimized crystal structures}

Calculations are performed on the hexagonal HT structures of Jansen and Waidmann [1] as well as on the triclinic LT structures of Dinnebier et al. [3]. Because the atomic positions in the unit cells of the HT structures are unknown, several different atomic configurations are designed as starting points for the structure optimizations. Physically and chemically reasonable configurations can only be designed when the experimental determined space group symmetry $\mathrm{P} 6 / \mathrm{mmm}$ is reduced.

One designed configuration of $\mathrm{C}_{60} \cdot 2 \mathrm{CHCl}_{3}$ has $\mathrm{P} \overline{3}$ symmetry. The two chloroform molecules in the unit cell are located in the trigonal prismatic voids at $(1 / 3,2 / 3,1 / 2)$ and $(2 / 3,1 / 3,1 / 2)$, respectively, and are related by inversion symmetry. One six-fold axis of the $\mathrm{C}_{60}$ and the $C_{3}$-axes of the $\mathrm{CHCl}_{3}$ molecules coincide with the $c$ axis of the hexagonal lattice. The two $\mathrm{C}-\mathrm{H}$ bonds point towards the $-c$ and $+c$ lattice vector, respectively. Three other start configurations are derived from the $\mathrm{P} \overline{3}_{H T}$ configuration by exchanging the hydrogen atoms of the $\mathrm{CHCl}_{3}$ molecules with arbritrary chlorine atoms. Two of these configurations have P1 symmetry and one has $\mathrm{P} \overline{1}$ symmetry. Due to the exchange of $\mathrm{H}$ and $\mathrm{Cl}$ atoms the $\mathrm{CHCl}_{3}$ molecules are differently oriented and probably induce also an orientational change of the $\mathrm{C}_{60}$ molecules. Throughout this article all configurations are named by their symmetry labels, i.e. the configurations formed are termed $\mathrm{P}_{H T}, \mathrm{P}_{H T}^{\prime}, \mathrm{P} \overline{3}_{H T}$ and $\mathrm{P} \overline{1}_{H T}$. The most stable configuration of $\mathrm{C}_{60} \cdot 2 \mathrm{CHCl}_{3}$, i.e. the one with the lowest calculated energy, is used to form the starting configuration for the structure optimizations of $\mathrm{C}_{60} \cdot 2 \mathrm{CHBr}_{3}$.

For the calculations on pure fcc $\mathrm{C}_{60}$ the crystal structure of David is employed [14]. The space group of this structure is $\mathrm{Fm} \overline{3}$, i.e. all molecules have the same orientation. Its primitive unit cell contains one molecule [Fig. 1](c)] and has a length of $a=9.949 \AA$ (Table $\mathbb{1}$ ).

It is worth noting that both $\mathrm{CHCl}_{3}$ and $\mathrm{CHBr}_{3}$ have permanent electric dipole moments of $\mu \sim 1 \mathrm{D}[20]$ and the $\mathrm{C}_{60}$ molecules are highly polarizable $\left(\alpha \sim 80 \AA^{3}[21]\right)$. The charge distribution within the haloform molecules is such that the halogen atoms are charged partially negatively and the hydro- gen atoms are charged partially positively. Hence, the stability of $\mathrm{C}_{60} \cdot 2 \mathrm{CHX}_{3}(\mathrm{X}=\mathrm{Cl}, \mathrm{Br})$ is presumably mainly due to dipole-induced dipole interactions rather than by van-derWaals interactions between the molecules.

Table II summarizes the relative energies, $\Delta E$, between the optimized crystal structures of neutral $\mathrm{C}_{60} \cdot 2 \mathrm{CHCl}_{3}$ and $\mathrm{C}_{60} \cdot 2 \mathrm{CHBr}_{3}$. All energies are with respect to the most stable configurations which have relative energies of $\Delta E=$ $0 \mathrm{~kJ} \cdot \mathrm{mol}^{-1}$. The most stable structures of $\mathrm{C}_{60} \cdot 2 \mathrm{CHCl}_{3}$ are the $\mathrm{P} 1_{H T}$ configurations [Fig. 11(a)]. The energy difference to the next stable configuration $\left(\mathrm{P} \overline{3}_{H T}\right)$ is only $3 \mathrm{~kJ} \cdot \mathrm{mol}^{-1}$. Although the LT configurations correspond to temperatures below $\sim 150 \mathrm{~K}$ and the HT structures to room temperature, the calculations on $\mathrm{C}_{60} \cdot 2 \mathrm{CHCl}_{3}$ yields a lower energy for the $\mathrm{P} 1_{H T}$ configuration than for the $\mathrm{P}_{L T}$ configuration. The energy difference is $\Delta E=28 \mathrm{~kJ} \cdot \mathrm{mol}^{-1}$. In the case of $\mathrm{C}_{60} \cdot 2 \mathrm{CHBr}_{3}$ both structures, $\mathrm{P}_{H T}$ and $\mathrm{P} \overline{1}_{L T}$, have nearly identical energies.

These energy considerations are made for zero temperature and, therefore, do not include any entropic effects. The energies shall give only a clue about the shape of the potential energy surface of $\mathrm{C}_{60} \cdot 2 \mathrm{CHX}_{3}(\mathrm{X}=\mathrm{Cl}, \mathrm{Br})$. The small energy differences between the configurations give rise to a shallow potential energy surface provided that the energy barriers of molecular re-orientations are of the same order as the relative energies. Solid-state NMR measurements predicted for the re-orientations of the $\mathrm{C}_{60}$ molecules in $\mathrm{C}_{60} \cdot 2 \mathrm{CHBr}_{3}$ activation energies of $6 \mathrm{~kJ} \cdot \mathrm{mol}^{-1}[4]$. Nevertheless, in order to give a more precise answer of the relative stability between the configurations $\mathrm{C}_{60} \cdot 2 \mathrm{CHCl}_{3}$ and $\mathrm{C}_{60} \cdot 2 \mathrm{CHBr}_{3}$ at least the zero-point vibrational energy and the vibrational partition function need to be calculated.

All optimized structures of $\mathrm{C}_{60} \cdot 2 \mathrm{CHX}_{3}(\mathrm{X}=\mathrm{Cl}, \mathrm{Br})$, obtained from the HT and LT data have almost identical intramolecular atomic distances (in $\mathrm{pm}$ ): $R(\mathrm{C}-\mathrm{C})=145$, $R(\mathrm{C}=\mathrm{C})=140, R(\mathrm{C}-\mathrm{H})=109, R(\mathrm{C}-\mathrm{Cl})=177-179, R(\mathrm{C}-\mathrm{Br})$ $=194-196$. These distances are equivalent to the appropriate distances of free molecules in the gas phase.

The main differences between the calculated structures can be found when comparing the intermolecular distances. The differently oriented haloform molecules in the start configuration of the optimization procedure induce changes in the orientation of the fullerene molecules. We note that for both chloroform and bromoform intercalation the high resolution $\mathrm{X}$-ray measurements [3] and the calculated LT structures (this work) are almost identical. The largest differences between these structures are in the intermolecular distances and are smaller than $5 \mathrm{pm}$. This means, the optimization of the atomic positions of the LT structures with fixed lattice parameters does not cause any drastical structural changes.

Table III summarizes selected intermolecular distances of the optimized crystal structures of neutral fcc $\mathrm{C}_{60}$ and of neutral $\mathrm{C}_{60} \cdot 2 \mathrm{CHX}_{3}(\mathrm{X}=\mathrm{Cl}, \mathrm{Br})$. While the expansion of the lattice of $\mathrm{C}_{60}$ molecules caused by the intercalation is accompanied by an increase of the unit cell length of only 1 to $4 \%$ the changes of the shortest distances between $\mathrm{C}_{60}$ molecules vary between 1 and $18 \%$. This indicates that there are changes in the orientation of the molecules. Due to the larger effec- 
TABLE II: Relative energies between the different configurations $\left(\Delta E\right.$, in $\left.\mathrm{kJ} \cdot \mathrm{mol}^{-1}\right)$ and selected intermolecular atomic distances (in pm) of several calculated structures of neutral $\mathrm{fcc}_{60} \mathrm{C}_{60}$ and $\mathrm{C}_{60} \cdot 2 \mathrm{CHX}_{3}(\mathrm{X}=\mathrm{Cl}, \mathrm{Br})$. Summarized are the shortest distances and, if given, the corresponding average values in parenthesis. Note, the distances of fcc $\mathrm{C}_{60}$ are related to the primitive unit cell [Fig. 11(c)]

\begin{tabular}{|c|c|c|c|c|c|c|c|}
\hline & $\Delta E$ & $\frac{\mathrm{C} \cdots \mathrm{C}\left(\mathrm{C}_{60}\right)}{\text { along } a, b}$ & along $a+b$ & along $c$ & $\begin{array}{c}\left.C \cdot X^{a}\right) \\
\left(C_{60}\right)\end{array}$ & $X \cdots X^{\mathbf{b})}$ & $\begin{array}{c}\left.\mathrm{C} \cdots \mathrm{H}^{\mathbf{b}}\right) \\
\left(\mathrm{C}_{60}\right) \\
\end{array}$ \\
\hline \multicolumn{8}{|l|}{ fcc $C_{60}$ c) } \\
\hline $\mathrm{Fm} \overline{3}$ & & $\left.299,301^{f}\right)$ & $315^{f)}$ & $342^{f)}$ & & & \\
\hline \multicolumn{8}{|l|}{$\mathrm{C}_{60} \cdot 2 \mathrm{CHCl}_{3}$} \\
\hline $\left.\mathrm{P} 1_{H T} \mathbf{d}\right)$ & 0 & 340,302 & 340 & 354 & 301 (339) & $308(348)$ & $262(347)$ \\
\hline $\left.\mathrm{P} \overline{3}_{H T} \mathbf{d}\right)$ & 3 & 306,306 & 306 & 362 & 355 & 350 & 334 (359) \\
\hline $\left.\mathrm{P} 1_{H T}^{\prime} \mathbf{d}\right)$ & 11 & 304,302 & 346 & 355 & 317 (338) & $298(328)$ & $295(345)$ \\
\hline $\left.\mathrm{P} \overline{1}_{H T}^{-1+1} \mathbf{d}\right)$ & 14 & 303,302 & 351 & 356 & $319(342)$ & $305(326)$ & 303 (357) \\
\hline $\left.\mathrm{P} \overline{1}_{L T} \mathbf{e}\right)$ & 28 & $326,324 \mathrm{~g})$ & $\left.340^{g}\right)$ & $\left.361^{g}\right)$ & 339 (347) & $\ldots$ & $269(335)$ \\
\hline \multicolumn{8}{|l|}{$\mathrm{C}_{60} \cdot 2 \mathrm{CHBr}_{3}$} \\
\hline $\left.\mathrm{P} 1_{H T} \mathbf{d}\right)$ & 0 & 354,335 & 343 & 360 & $300(341)$ & $318(342)$ & $251(342)$ \\
\hline $\left.\mathrm{P} \overline{1}_{L T} \mathbf{e}\right)$ & 1 & $332,334 \mathbf{g})$ & $\left.354^{g}\right)$ & $\left.385^{g}\right)$ & 343 (349) & $\ldots$ & $286(337)$ \\
\hline
\end{tabular}

a) Distances shorter than $357 \mathrm{pm} .{ }^{\text {b) }}$ Distances shorter than $400 \mathrm{pm} .{ }^{\text {c) }}$ Crystal structure of David [14]. ${ }^{\text {d) }}$ Crystal structure of Jansen and Waidmann [1]. e) Crystal structure of Dinnebier et al. [3]. f) The $c$ vector of the hexagonal unit cell corresponds to the $b$ vector of the primitive fcc unit cell. ${ }^{\text {g) }}$ The $c$ vector of the hexagonal unit cell corresponds to the $b$ vector of the triclinic unit cell used in Ref. [3].

tive volume of $\mathrm{CHBr}_{3}$ the shortest interatomic distances between neighboring $\mathrm{C}_{60}$ molecules are on the average larger for $\mathrm{C}_{60} \cdot 2 \mathrm{CHBr}_{3}$ than for $\mathrm{C}_{60} \cdot 2 \mathrm{CHCl}_{3}$ and fcc $\mathrm{C}_{60}$. But the largest changes are found for the shortest distance between $\mathrm{C}$ atoms of nearest neighboring $\mathrm{C}_{60}$ molecules along the cell vector $a, R(\mathrm{C} \cdots \mathrm{C})_{a}$, of the $\mathrm{P}_{H T}$ structures, which are 41 $(\mathrm{X}=\mathrm{Cl})$ and $53 \mathrm{pm}(\mathrm{X}=\mathrm{Br})$. Note, that the distances of fcc $\mathrm{C}_{60}$ are related to the primitive unit cell [Fig. 11(c)].

All the shortest $\mathrm{C} \cdots \mathrm{C}$ distances along the $c$ vector, $R(\mathrm{C} \cdots \mathrm{C})_{c}$, of the $\mathrm{HT}$ as well as the LT structures are larger than the shortest $\mathrm{C} \cdots \mathrm{C}$ distances in the (0001) plane, typical for layered system structures. By far the largest $R(\mathrm{C} \cdots \mathrm{C})_{c}$ value of $385 \mathrm{pm}$ is for the $\mathrm{P}_{L T}$ configuration of $\mathrm{C}_{60} \cdot 2 \mathrm{CHBr}_{3}$.

Both in fcc $\mathrm{C}_{60}$ and the HT structures of $\mathrm{C}_{60} \cdot 2 \mathrm{CHCl}_{3}$ there is at least one value of $R(\mathrm{C} \cdots \mathrm{C})_{a}$ or $R(\mathrm{C} \cdots \mathrm{C})_{b}$ which is around $300 \mathrm{pm}$. These distances are about $40 \mathrm{pm}$ smaller than the sum of the van-der-Waals radii of two carbon atoms $\left(R_{v d W}(\mathrm{C})=170 \mathrm{pm}\right.$ 22] $)$. This is evidence for an overlap between $\pi$ orbitals of neighboring $\mathrm{C}_{60}$ molecules. While the $\mathrm{P}^{-}{ }_{L T}$ and most of the HT structures of $\mathrm{C}_{60} \cdot 2 \mathrm{CHCl}_{3}$ have almost identical values for $R(\mathrm{C} \cdots \mathrm{C})_{a}$ and $R(\mathrm{C} \cdots \mathrm{C})_{b}$ only $\mathrm{P}_{H T} \mathrm{C}_{60} \cdot 2 \mathrm{CHCl}_{3}$ has two different values, where $R(\mathrm{C} \cdots \mathrm{C})_{a}$ is about $40 \mathrm{pm}$ larger than $R(\mathrm{C} \cdots \mathrm{C})_{b}$. Because of symmetry restrictions for $\mathrm{P}_{3 T} \mathrm{C}_{60} \cdot 2 \mathrm{CHCl}_{3}$, all the shortest intermolecular C $\cdots \mathrm{C}$ distances in the (0001) plane, $R(\mathrm{C} \cdots \mathrm{C})_{a}, R(\mathrm{C} \cdots \mathrm{C})_{b}$ and $R(\mathrm{C} \cdots \mathrm{C})_{a+b}$, are equivalent.

On the other hand the LT configuration of $\mathrm{C}_{60} \cdot 2 \mathrm{CHCl}_{3}$ $\left(\mathrm{P} \overline{1}_{L T}\right)$ does not have any interatomic distance between neighboring $\mathrm{C}_{60}$ molecules which is shorter than $324 \mathrm{pm}$. But the values of $R(\mathrm{C} \cdots \mathrm{C})_{a}$ and $R(\mathrm{C} \cdots \mathrm{C})_{b}$ are also almost identical, similar to fcc $\mathrm{C}_{60}$.

In both structures of $\mathrm{C}_{60} \cdot 2 \mathrm{CHBr}_{3}$ considered only $R(\mathrm{C} \cdots \mathrm{C})_{b}$ are shorter than $340 \mathrm{pm}$, the sum of the van-derWaals radii of two carbon atoms. Similar to $\mathrm{C}_{60} \cdot 2 \mathrm{CHCl}_{3}$ the $\mathrm{P}_{H T}$ structure of $\mathrm{C}_{60} \cdot 2 \mathrm{CHBr}_{3}$ has two different values for
$R(\mathrm{C} \cdots \mathrm{C})_{a}$ and $R(\mathrm{C} \cdots \mathrm{C})_{b}$ while for $\mathrm{P} \overline{1}_{L T}$ these distances are almost identical.

For all configurations both the average values and the smallest values of the distances between the halogen atoms $\mathrm{X}$ $(\mathrm{X}=\mathrm{Cl}, \mathrm{Br})$ and the atoms of the $\mathrm{C}_{60}$ molecules are smaller than the sum of the corresponding van-der-Waals radii $\left(R_{v d W}(\mathrm{Cl})=\right.$ $175 \mathrm{pm}, R_{v d W}(\mathrm{Br})=185 \mathrm{pm}$ [22]). The $\mathrm{P}_{H T}$ configurations of $\mathrm{C}_{60} \cdot 2 \mathrm{CHCl}_{3}$ and $\mathrm{C}_{60} \cdot 2 \mathrm{CHBr}_{3}$ have the smallest value of $R(\mathrm{C} \cdots \mathrm{X}) \approx 300 \mathrm{pm}$. This indicates a significant intermolecular overlap between orbitals of $\mathrm{C}_{60}$ and $\mathrm{CHX}_{3}$.

Due to their partial negative charge the halogen atoms of neighboring haloform molecules should avoid each other. Therefore, it is peculiar that the majority of the configurations have halogen atoms $\mathrm{X}$ that are closer than twice of $R_{v d W}(\mathrm{X})$. Only the $\mathrm{P} \overline{1}_{L T}$ structures do not have any $\mathrm{X} \cdots \mathrm{X}$ distance smaller than $400 \mathrm{pm}$.

All configurations have similar average values of the nonbonding $\mathrm{C} \cdots \mathrm{H}$ distances. The $\mathrm{P}_{H T}$ structures have the shortest non-bonding $\mathrm{C} \cdots \mathrm{H}$ distances. Apparently, the partially positively charged $\mathrm{H}$ atoms are attracted by the negatively charged $\pi$ electron system of the $\mathrm{C}_{60}$ molecules.

The electronic structure calculations of the following sections are performed representatively for the most stable $\left(\mathrm{P} 1_{H T}\right)$ and most unstable $\left(\mathrm{P} \overline{1}_{L T}\right)$ configurations as determined in this section. It is assumed that the other structures have similar properties which can be derived or approximated from the properties of the $\mathrm{P} 1_{H T}$ and $\mathrm{P} \overline{1}_{L T}$ configurations.

\section{B. Electronic structures}

\section{Band structures and DOS}

Fig. 3 shows the valence and conduction bands of neutral $\mathrm{P}_{H T} \mathrm{C}_{60} \cdot 2 \mathrm{CHX}_{3}(\mathrm{X}=\mathrm{Cl}, \mathrm{Br})$. The corresponding Brillouin zone is depicted in Fig. 2. The systems have indirect 


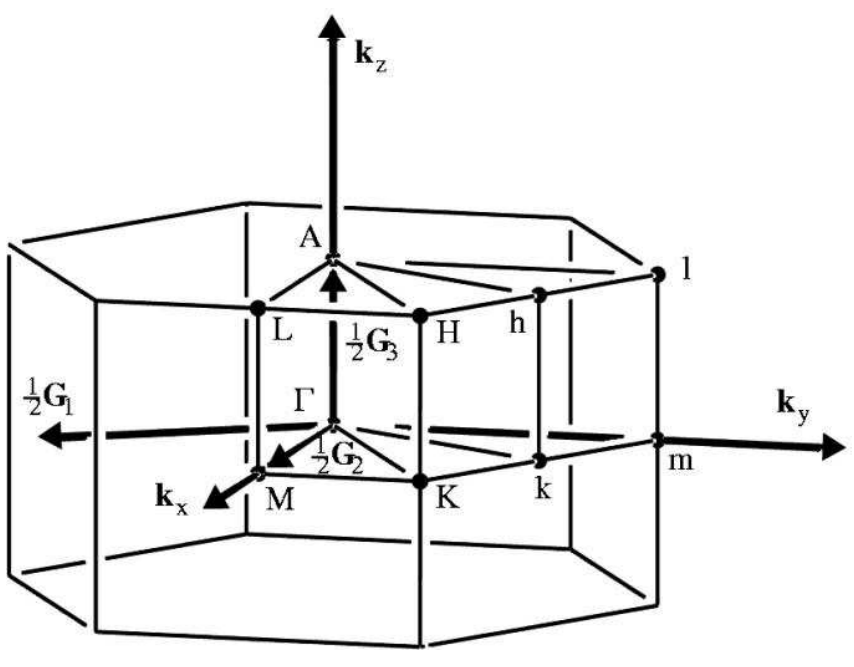

FIG. 2: Hexagonal Brillouin zone with reduced symmetry.

band gaps of $1.2(\mathrm{X}=\mathrm{Cl})$ and $1.3 \mathrm{eV}(\mathrm{X}=\mathrm{Br})$. Since neutral $\mathrm{C}_{60} \cdot 2 \mathrm{CHX}_{3}$ has empty conduction bands the systems are non-metallic. Their valence bands (VB) and conduction bands (CB) consist of five and three narrow bands, respectively, in accordance with the respective degeneracy of the constitutive molecular orbitals. The total DOS of the CB clearly show three nearly separated peaks, each belonging to one of the three bands. None of the VB and CB are degenerate at any $k$ vector of the band structure. The largest band dispersions are along $k_{x}$ and $k_{y}$. Table III collects the width of the VB and $\mathrm{CB}$ and the smallest indirect gaps between $\mathrm{VB}$ and $\mathrm{CB}$. The widths of the $\mathrm{VB}$ and $\mathrm{CB}$ of $\mathrm{P}_{H T} \mathrm{C}_{60} \cdot 2 \mathrm{CHBr}_{3}$ are 0.4 and $0.3 \mathrm{eV}$, respectively. The $\mathrm{VB}$ of $\mathrm{P}_{H T} \mathrm{C}_{60} \cdot 2 \mathrm{CHCl}_{3}$ is $0.1 \mathrm{eV}$ broader, because the fullerene molecules are closer to each other (see Tab. II) and, hence, the overlap of the $\pi$ orbitals of neighboring molecules is larger. Note, that the band structure of neutral $\mathrm{C}_{60} \cdot 2 \mathrm{CHBr}_{3}$ has a distinguishing feature namely

TABLE III: Comparison of width and smallest indirect gaps for the valence and conduction bands, $\mathrm{VB}$ and $\mathrm{CB}$, respectively (in eV) calculated for fcc $\mathrm{C}_{60}$ and neutral $\mathrm{C}_{60} \cdot 2 \mathrm{CHX}_{3}(\mathrm{X}=\mathrm{Cl}, \mathrm{Br})$.

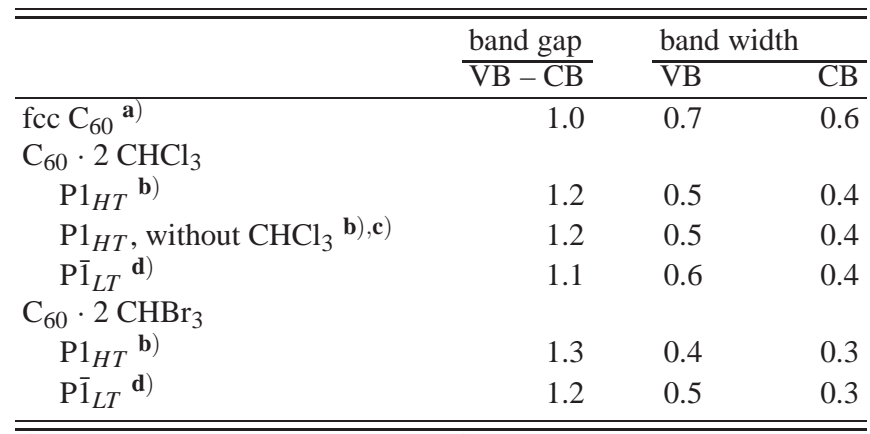

$\overline{\text { a) Crystal structure of David [14]. b) Crystal structure of Jansen and }}$ Waidmann [1]. c) The two $\mathrm{CHCl}_{3}$ molecules are simply deleted from the unit cell of the $\mathrm{P}_{H T}$ structure and the remaining $\mathrm{C}_{60}$ molecule is re-optimized. ${ }^{\mathbf{d})}$ Crystal structure of Dinnebier et al. [3]. that a single narrow band appears just $0.4 \mathrm{eV}$ below the VB. In the case of $\mathrm{C}_{60} \cdot 2 \mathrm{CHCl}_{3}$ the electronic states below the VB are rather a group of bands. The gap between the latter and the VB is about $0.5 \mathrm{eV}$.

The LT structures have similar band structures as the $\mathrm{P}_{H T}$ structures but with band gaps of $1.1\left(\mathrm{C}_{60} \cdot 2 \mathrm{CHCl}_{3}\right)$ and 1.2 $\left(\mathrm{C}_{60} \cdot 2 \mathrm{CHBr}_{3}\right)$. For both, $\mathrm{C}_{60} \cdot 2 \mathrm{CHCl}_{3}$ and $\mathrm{C}_{60} \cdot 2 \mathrm{CHBr}_{3}$, the width of the VB is $0.1 \mathrm{eV}$ larger than that of the appropriate HT structure in agreement with the intermolecular distances of Table [1]. The widths of the CB and the gaps between the VB and the upper edge of the next lower lying electronic states are identical for the HT and LT structures.

For fcc $\mathrm{C}_{60}$ the calculated band gap is only $1.0 \mathrm{eV}$ and the valence and conduction bands are 0.1 to $0.3 \mathrm{eV}$ broader than the VB and CB of the HT and LT structures. Both, the smaller band gap and the broader bands are due to smaller distances between the fullerene molecules as compared to $\mathrm{C}_{60} \cdot 2 \mathrm{CHX}_{3}$ $(\mathrm{X}=\mathrm{Cl}, \mathrm{Br})$.

In order to disentangle the contribution of the chloroform molecules to the electronic structure of the $\mathrm{C}_{60}$ subsystem in $\mathrm{C}_{60} \cdot 2 \mathrm{CHCl}_{3}$, calculations are also performed on a hypothetical hexagonal lattice of $\mathrm{C}_{60}$ molecules in the geometry of $\mathrm{P}_{H T} \mathrm{C}_{60} \cdot 2 \mathrm{CHCl}_{3}$. This model system is designed by simply removing the two $\mathrm{CHCl}_{3}$ molecules from the unit cell of $\mathrm{P}_{H T} \mathrm{C}_{60} \cdot 2 \mathrm{CHCl}_{3}$. The shape and the positions of the valence and conduction bands almost do not change. The band gap of $1.2 \mathrm{eV}$ and the widths of the $\mathrm{VB}$ and $\mathrm{CB}$ are identical to those of $\mathrm{P}_{H T} \mathrm{C}_{60} \cdot 2 \mathrm{CHCl}_{3}$. Hence, the chloroform as well as the bromoform molecules apparently do not affect the band structure of the materials substantially.

One of the well-known drawbacks of DF calculations is the underestimation of band gaps. For instance, the experimental determined band gap of fcc $\mathrm{C}_{60}$ is $2.3 \mathrm{eV}$ [23] whereas the calculated gap is less than half of that (vide supra). Hence, the band gaps presented in this article are only lower bounds. The problem of too small band gaps in DF calculations can be cured according to Slater transition-state methods [24, 25].

\section{Partial DOS}

Fig. 7 shows the partial density of states (PDOS) for specific atoms of $\mathrm{P}_{H T} \mathrm{C}_{60} \cdot 2 \mathrm{CHX}_{3}(\mathrm{X}=\mathrm{Cl}, \mathrm{Br})$. The PDOS is the decomposition of the electron bands into contributions of atomic orbitals (AO). The atoms of $\mathrm{C}_{60}$ and the haloform molecules chosen for the PDOS have the smallest intermolecular $\mathrm{C} \cdots \mathrm{X}$ distances. As expected, the $\mathrm{VB}$ and the $\mathrm{CB}$ of $\mathrm{P}_{H T} \mathrm{C}_{60} \cdot 2 \mathrm{CHCl}_{3}$ and $\mathrm{C}_{60} \cdot 2 \mathrm{CHBr}_{3}$ mainly consist of carbon $2 p_{\pi}$ AO. Surprisingly, also chlorine $3 p$ and bromine $4 p \mathrm{AO}$ contribute significantly to the PDOS of $\mathrm{P}_{H T}$ $\mathrm{C}_{60} \cdot 2 \mathrm{CHCl}_{3}$ and $\mathrm{C}_{60} \cdot 2 \mathrm{CHBr}_{3}$, respectively. However, the latter two contributions are smaller than that of the $\mathrm{C}_{60}$ atoms. The single electronic band just below the $\mathrm{VB}$ of $\mathrm{P}_{H T}$ $\mathrm{C}_{60} \cdot 2 \mathrm{CHBr}_{3}$ (Fig. 3) mainly consists of bromine $4 p \mathrm{AO}$.

The calculated PDOS for the LT structures leads to conclusions similar to those for the HT structures. However, the contributions of the $p$-type orbitals of the halogen atoms are smaller and the contribution of fullerenes correspondingly 

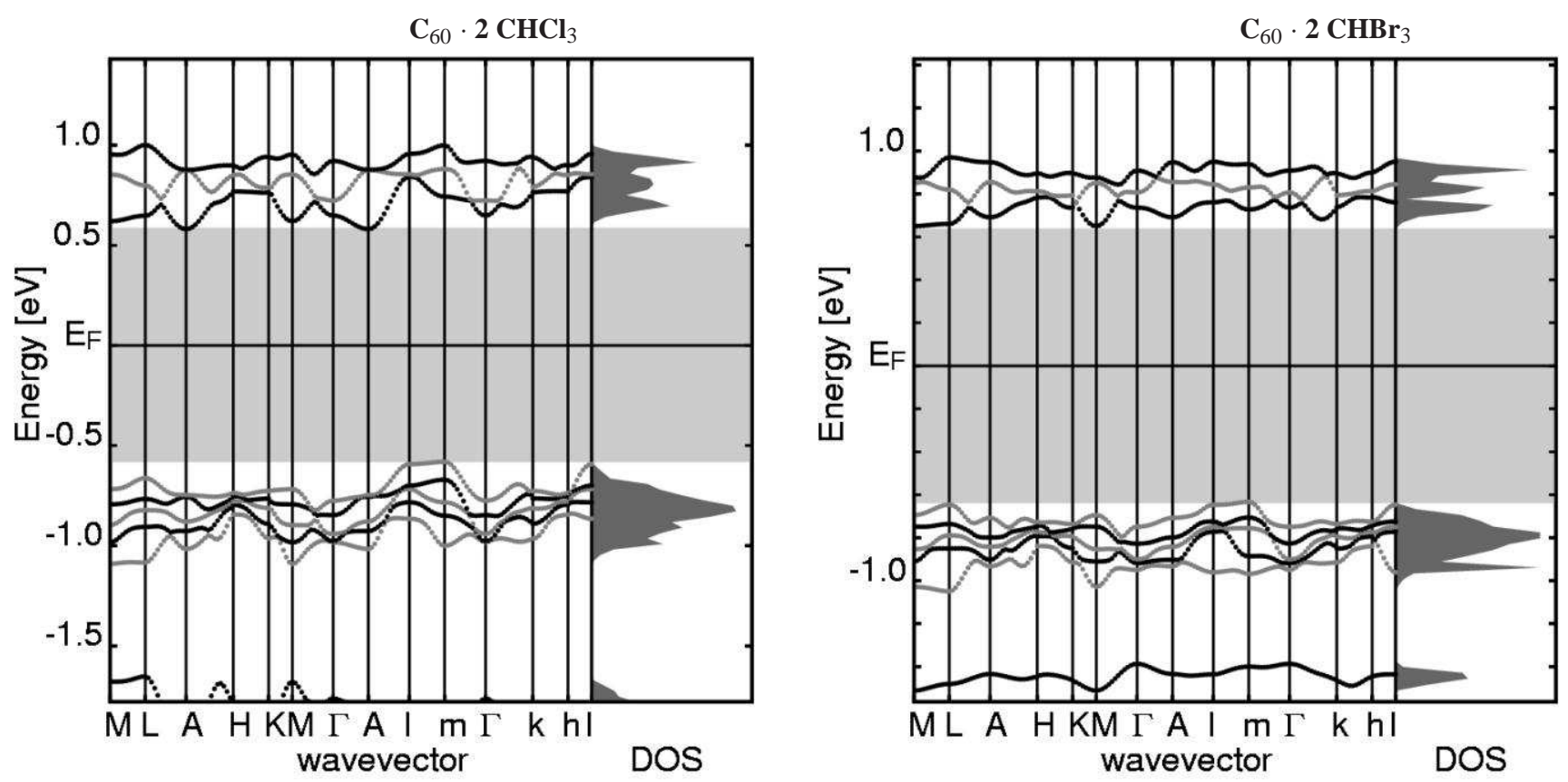

FIG. 3: One-electron band structures and total density of states (DOS) of neutral $\mathrm{P}_{H T} \mathrm{C}_{60} \cdot 2 \mathrm{CHX}_{3}(\mathrm{X}=\mathrm{Cl}, \mathrm{Br}$ ). All energies are with respect to the Fermi energy, $E_{F}$. The band structures depict the three conduction bands, the five valence bands and the next state below the valence bands. For clarity, the bands are gray and black in alternating order.

larger, because the LT structures have larger intermolecular $\mathrm{C} \cdots \mathrm{X}(\mathrm{X}=\mathrm{Cl}, \mathrm{Br})$ distances on average.

Consequently, the haloform molecules do not only have the function of inert spacers to expand the $\mathrm{C}_{60}$ lattice as inferred in Section IV B 1 but might also support charge transfer and electron-phonon coupling.

\section{Charge distribution}

This section concerns only neutral $\mathrm{P}_{H T} \mathrm{C}_{60} \cdot 2 \mathrm{CHCl}_{3}$ because neutral $\mathrm{P}_{H T} \mathrm{C}_{60} \cdot 2 \mathrm{CHBr}_{3}$ and neutral $\mathrm{P}_{L T}$ $\mathrm{C}_{60} \cdot 2 \mathrm{CHX}_{3}(\mathrm{X}=\mathrm{Cl}, \mathrm{Br})$ have akin charge density distributions.

Figs. F(a) and 5 (b) show contour plots of the valence charge density in the (1100) and (1100) planes, respectively. The valence charge density is the sum of the squares of the five highest occupied crystal orbitals of neutral $\mathrm{C}_{60} \cdot 2 \mathrm{CHCl}_{3}$. The integral over the Brillouin zone is obtained using the midpoint approximation ( $\Gamma$ point). In the corner of the maps are parts of the $\mathrm{C}_{60}$ molecules represented by their $\pi$ electron systems. Clearly visible are the carbon $2 p_{\pi} \mathrm{AO}$. In the center of Fig 5 (a) valence charge density that belongs to the two $\mathrm{CHCl}_{3}$ molecules can be seen. Both density plots show considerable overlap of the $p_{\pi}$ orbitals of adjacent $\mathrm{C}_{60}$ molecules as well as overlap of the chlorine $p$ orbitals with the $\pi$ electron systems of the $\mathrm{C}_{60}$ molecules. The latter overlap is smaller than the overlap between the $\pi$ electron systems, yet relevant.

The contour plots of Fig. 6 show the molecular deformation density, $\rho_{\text {diff }}$, in particular planes. The molecular deformation density is defined as the difference between the total electron density of $\mathrm{C}_{60} \cdot 2 \mathrm{CHCl}_{3}$ and the sum of the densities of the subsystems $\mathrm{C}_{60}$ and $\mathrm{CHCl}_{3}$. Note, that both subsystems have the same geometry as in $\mathrm{C}_{60} \cdot 2 \mathrm{CHCl}_{3}$. The molecular deformation density discloses changes of the electron density of the $\mathrm{C}_{60}$ and chloroform molecules due to intercalation, e.g. polarization effects or charge transfer from one molecule to another.

Fig. 6 (a) shows the changes of the electron density induced by chlorine atoms that have smallest interatomic distances to the $\mathrm{C}_{60}$ molecules. One chlorine atom pulls electron density away from $\mathrm{C}_{60}$ molecule and the other chlorine atom pushes electron density towards a $\mathrm{C}_{60}$ molecule. Both, Fig. $\mathrm{G}(\mathrm{b})$ and Fig. $6(\mathrm{c})$, depict the polarization of carbon-carbon $\pi$ bonds due to the two partially positively charged hydrogen atoms of the chloroform molecules. These hydrogen atoms have also the smallest interatomic distances to $\mathrm{C}_{60}$ atoms. The electron density surrounding the $\pi$-bonds is increased at the expense of the density around the hydrogen atoms.

Note that the deformation density is of the order of $10^{-4}$ atomic units and, hence, very small. However, the contour plots of Fig. 6 clearly validate the presumption of dipoleinduced dipole interactions between the haloform and the $\mathrm{C}_{60}$ molecules.

\section{Changes of the electronic structures due to charging}

In order to clarify how electron and hole doping affect the electronic structure and perhaps also the atomic configurations of haloform intercalated $\mathrm{C}_{60}$, calculations are performed on the charged $\mathrm{P}_{H T}$ and $\mathrm{P}_{L T}$ structures of $\mathrm{C}_{60} \cdot 2 \mathrm{CHX}_{3}$ $(\mathrm{X}=\mathrm{Cl}, \mathrm{Br})$ as well as on charged fcc $\mathrm{C}_{60}$. The structural changes of the $\mathrm{P}_{H T}$ and $\mathrm{P}_{L T}$ configurations of $\mathrm{C}_{60} \cdot 2 \mathrm{CHX}_{3}$ 

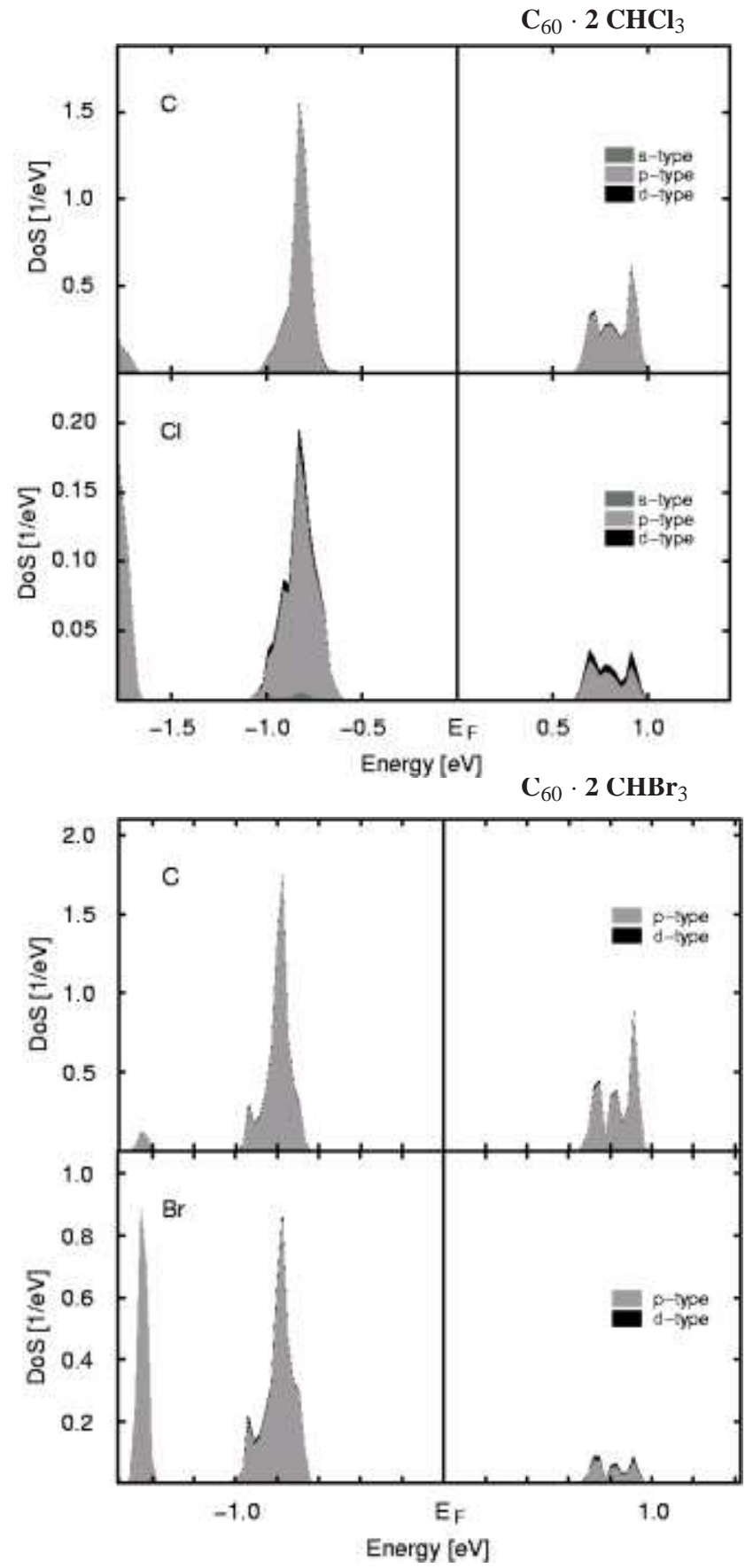

FIG. 4: Partial DOS of the bands depicted in Fig. B. All energies are with respect to the Fermi energy, $E_{F}$. The partial DOS show the contributions of the $s-, p$ - and $d$-type of orbitals of specific atoms of the $\mathrm{C}_{60}$ molecule, $\mathrm{C}$, and of the haloform molecules, $\mathrm{Cl}$ and $\mathrm{Br}$, to the total DOS of $\mathrm{P}_{H T} \mathrm{C}_{60} \cdot 2 \mathrm{CHX}_{3}(\mathrm{X}=\mathrm{Cl}, \mathrm{Br})$. Note the different ranges of the ordinates.

due to charging are found to be small. The charging has no effect on the intramolecular distances. For example Jahn-Teller distortion could not be found. The changes in intermolecular distances of Table II are of the order of 2 pm and are caused by small changes in the rotational orientation of the haloform and $\mathrm{C}_{60}$ molecules.

The Hirshfeld population analysis [26] predicted that in
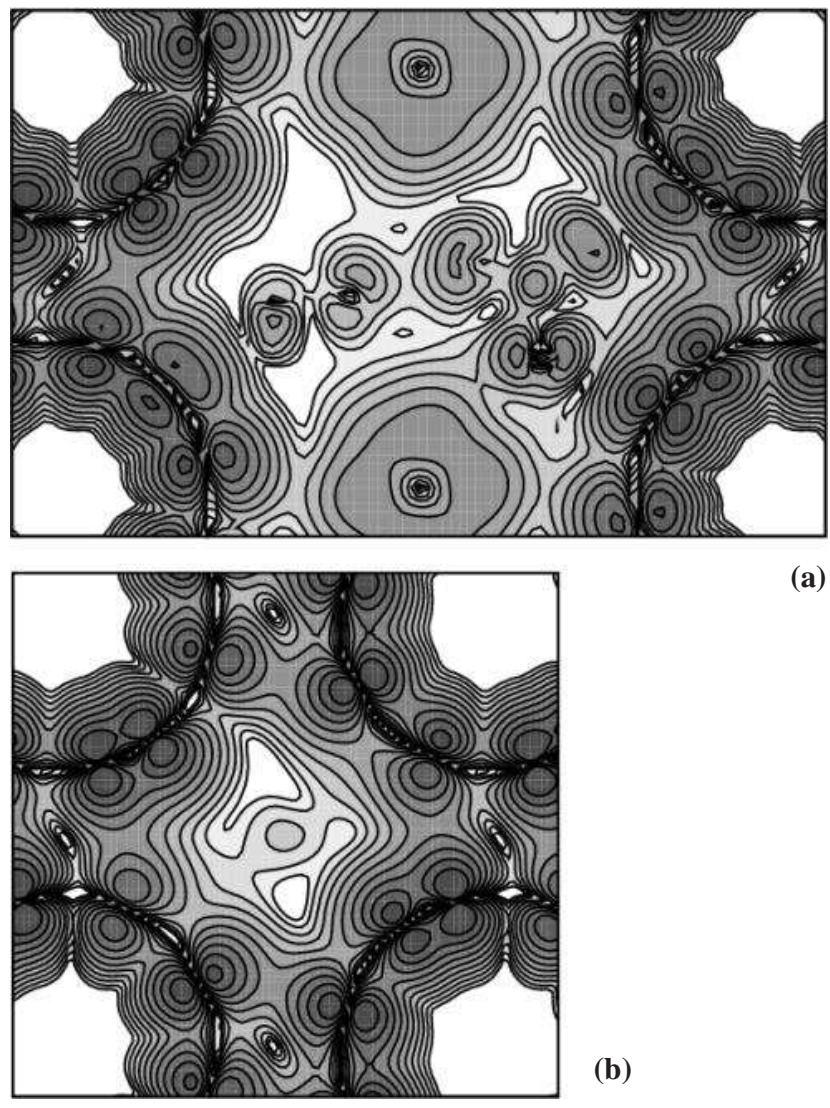

(a)

FIG. 5: Contour plots of the sum of the squares of the five highest occupied crystal orbitals at the $\Gamma$ point of neutral $\mathrm{P}_{H T} \mathrm{C}_{60} \cdot 2 \mathrm{CHCl}_{3}$ in the [(a)] (1100) and [(b)] (1100) planes. The iso-lines depict values from $10^{-5}$ to $5.12 \times 10^{-3}$ each increased by a factor of two $(1$ a.u. $=$ $6.7483 \times 10^{30}$ electrons $\left.\cdot \mathrm{m}^{-3}\right)$. The darker the gray the higher is the electron density.

each case $80 \%$ to $90 \%$ of the charge is located on the $\mathrm{C}_{60}$ molecules and the remaining part on the haloform molecules.

Fig. 7 shows the total DOS of the five valence and three conduction bands of neutral $\mathrm{C}_{60} \cdot 2 \mathrm{CHX}_{3}(\mathrm{X}=\mathrm{Cl}, \mathrm{Br})$ and their modifications upon hole and electron doping. In the following the terms $\mathrm{VB}$ and the $\mathrm{CB}$ are related to the corresponding states of the neutral systems. Overall the DOS of the VB and $\mathrm{CB}$ are narrow peaks with steep flanks. However, for the same charge the shape of the DOS of the HT and LT structures show differences. For almost all charges the $\mathrm{CB}$ has three distinct peaks which indicates that it consists of three narrow bands. The widths of the $\mathrm{CB}$ are in the range of $0.3-0.5 \mathrm{eV}$ without any clear trend with respect to charging. The width of the DOS of the five valence bands is between 0.4 to $0.6 \mathrm{eV}$ and the single bands are not resolved.

Significant are the shifts in energy of both VB and CB. Upon electron doping both the VB and the $\mathrm{CB}$ are shifted to higher energies whereas hole doping causes a shift to lower energies. The gap between the VB and the CB has its maximum at zero charge and decreases for positive as well as for negative charging by $0.1-0.2 \mathrm{eV}$. The gap between the VB and the states lower in energy as well as the gap between 

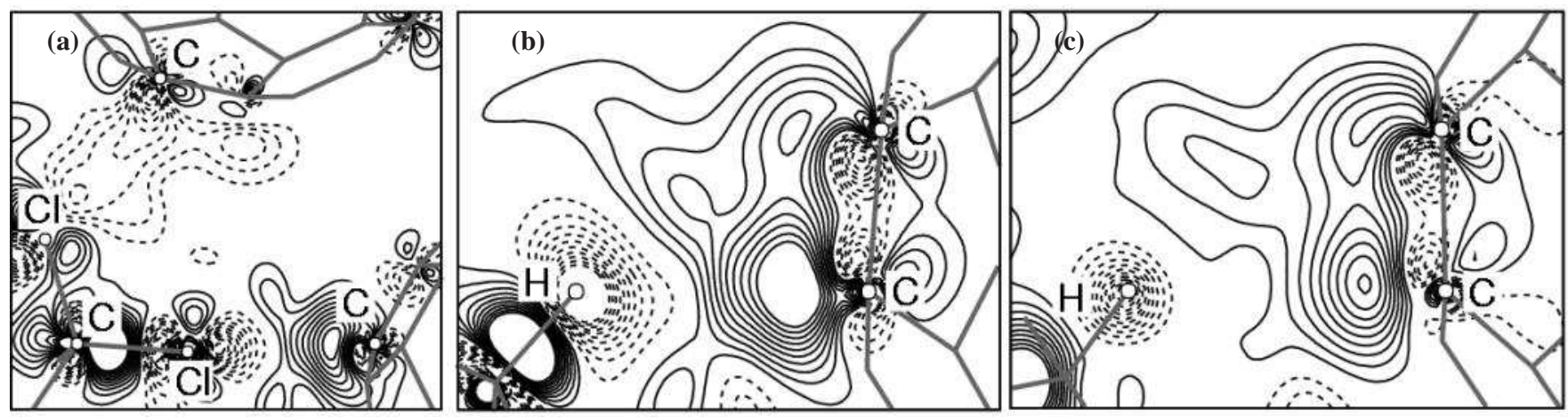

FIG. 6: Contour plots of the molecular deformation density, $\rho_{\text {diff }}$, plotted for relevant planes of $\mathrm{P}_{H T} \mathrm{C}_{60} \cdot 2 \mathrm{CHCl}_{3}$ (see text for the definition of $\rho_{\text {diff }}$ ). (a) shows the changes of the total density induced by $\mathrm{Cl}$ atoms, and (b) and (c) induced by the two $\mathrm{H}$ atoms in the unit cell. The atoms in and near the plane are marked by open circles. The iso-lines represent values from $-10^{-4}$ to $10^{-4}$ a.u. in steps of $10^{-5}$ a.u. . Dashed lines are for negative and solid lines for positive values. The light-gray solid lines sketch parts of the $\mathrm{CHCl}_{3}$ and $\mathrm{C}_{60} \mathrm{molecules}$

$\mathrm{C}_{60} \cdot 2 \mathrm{CHCl}_{3}$

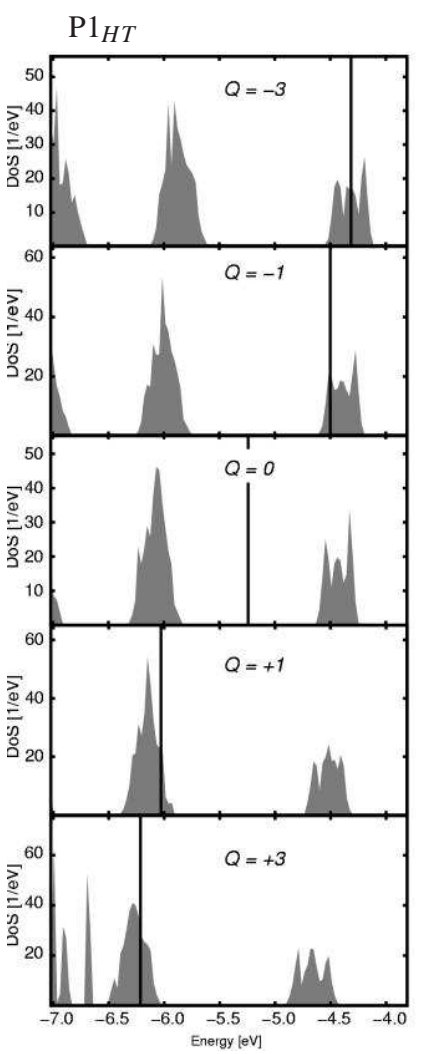

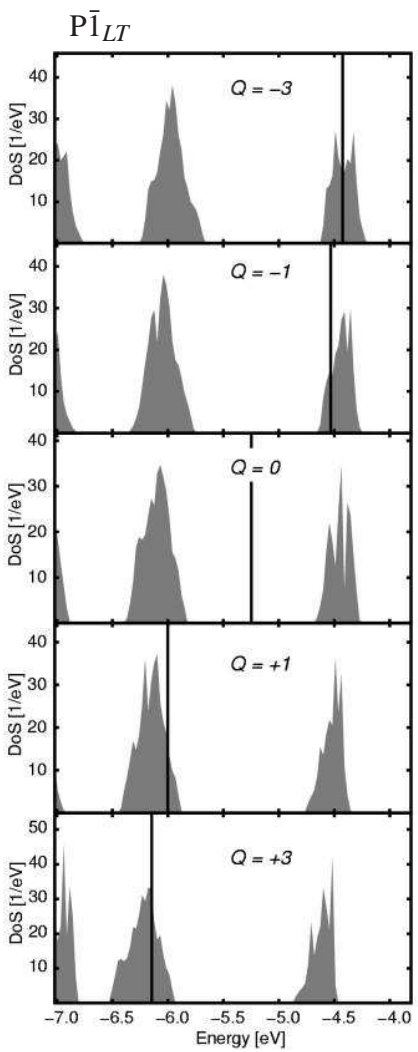

$\mathrm{C}_{60} \cdot 2 \mathrm{CHBr}_{3}$

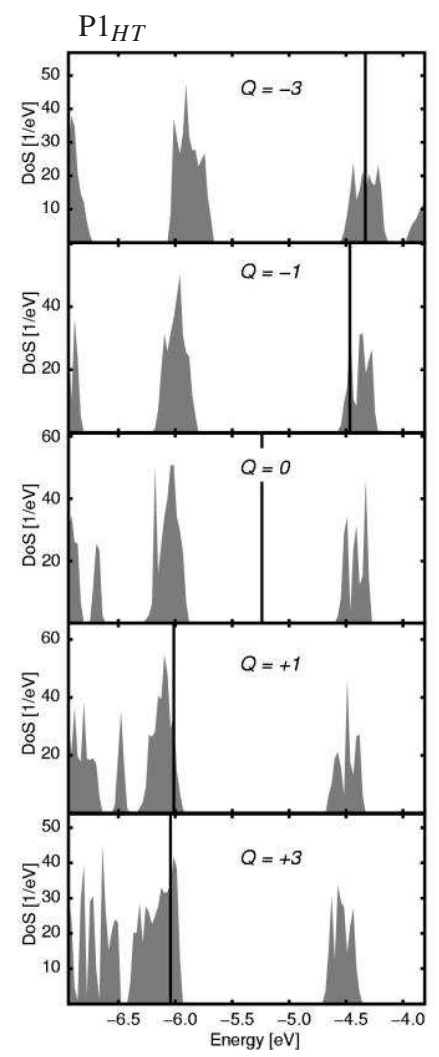

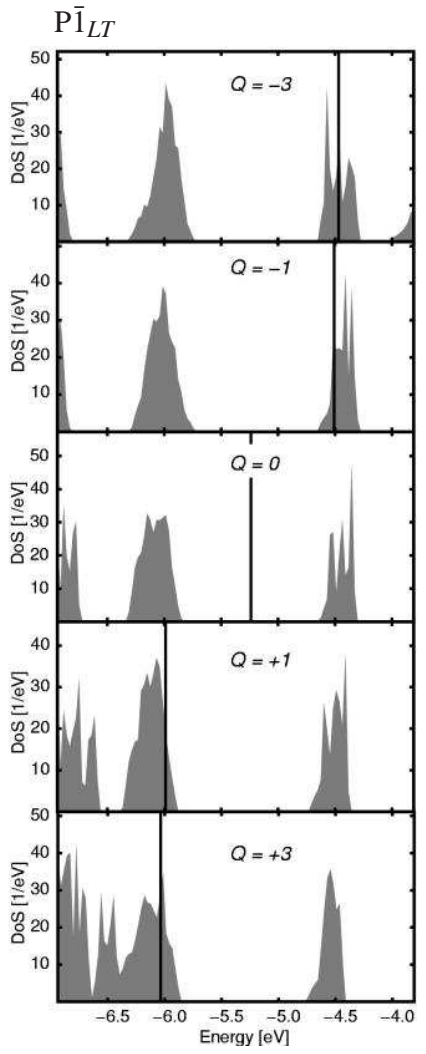

FIG. 7: Total density of states (DOS) around the Fermi energy, $E_{F}$, of the neutral and charged $\mathrm{P}_{H T}$ and $\mathrm{P}_{L T}$ structures of $\mathrm{C}_{60} \cdot 2 \mathrm{CHX} 3$ (X=Cl,Br). $Q$ is the total charge per unit cell. The vertical solid lines represent $E_{F}$. The corresponding total DOS at $E_{F}$ are summarized in Tab. IV.

the $\mathrm{CB}$ and the states higher in energy are also changed. In most of the cases the gap between the $\mathrm{CB}$ and the next higher bands is larger than $0.6 \mathrm{eV}$. However, for both structures of $\mathrm{C}_{60} \cdot 2 \mathrm{CHBr}_{3}$ and $Q=-3$ this gap is only $0.2 \mathrm{eV}$. For each structure of $\mathrm{C}_{60} \cdot 2 \mathrm{CHX}_{3}(\mathrm{X}=\mathrm{Cl}, \mathrm{Br})$ the gap between the $\mathrm{VB}$ and the next lower states is almost constant upon electron doping whereas for hole doping the VB are shifted towards lower energy and the next lower states towards higher energy. For $\mathrm{P}_{H T} \mathrm{C}_{60} \cdot 2 \mathrm{CHBr}_{3}$ and $Q=+3$ the former single band below the VB has merged with the latter, i.e. the gap has vanished. The VB is formed of six instead of five states. However, there is still a small gap of $\sim 0.1 \mathrm{eV}$ between these six bands and the next lower states. More drastic are the changes in the case of $\mathrm{P}_{L T} \mathrm{C}_{60} \cdot 2 \mathrm{CHBr}_{3}$ and $Q=+3$ where the $\mathrm{VB}$ and the 
TABLE IV: Total density of states (DOS) at the Fermi energy of charged pure fcc $\mathrm{C}_{60}$ and $\mathrm{C}_{60} \cdot 2 \mathrm{CHX}_{3}(\mathrm{X}=\mathrm{Cl}, \mathrm{Br})$. All values are in states per unit cell and $\mathrm{eV}$.

\begin{tabular}{|c|c|c|c|c|}
\hline$Q^{\text {a) }}$ & +3 & +1 & -1 & -3 \\
\hline $\begin{array}{l}\left.\text { fcc } \mathrm{C}_{60} \mathbf{b}\right) \\
\mathrm{C}_{60} \cdot 2 \mathrm{CHCl}_{3}\end{array}$ & 29 & 38 & 16 & 17 \\
\hline $\left.\mathrm{P} 1_{H T} \mathbf{c}\right)$ & 29 & 24 & 17 & 17 \\
\hline $\left.\mathrm{P} \overline{1}_{L T} \mathbf{e}\right)$ & 33 & 15 & 14 & 19 \\
\hline average $^{\text {f) }}$ & 31 & 20 & 16 & 18 \\
\hline $\mathrm{P}_{H T}$, without $\left.\left.\mathrm{CHCl}_{3} \mathbf{c}\right), \mathbf{d}\right)$ & 29 & 25 & 20 & 16 \\
\hline \multicolumn{5}{|l|}{$\mathrm{C}_{60} \cdot 2 \mathrm{CHBr}_{3}$} \\
\hline $\left.\mathrm{P} 1_{H T} \mathbf{c}\right)$ & 34 & 31 & 29 & 17 \\
\hline $\left.\mathrm{P} \overline{1}_{L T} \mathbf{e}\right)$ & 37 & 19 & 24 & 29 \\
\hline average $\mathbf{f})$ & 36 & 25 & 28 & 23 \\
\hline
\end{tabular}

a) Total charge per unit cell. ${ }^{\text {b) }}$ Crystal structure of David [14.

c) Crystal structure of Jansen and Waidmann [1]. d) The two $\mathrm{CHCl}_{3}$ molecules are simply deleted from the unit cell of the $\mathrm{P} 1_{H T}$ structure and the remaining $\mathrm{C}_{60}$ molecule is re-optimized. ${ }^{\mathbf{e})}$ Crystal structure of Dinnebier et al. [3]. f) Average of $\mathrm{P}_{H T}$ and $\mathrm{P}^{\overline{1}}{ }_{L T}$.

next lower states form a continuum.

Table IV summarizes the calculated total DOS at the Fermi energy of charged pure and haloform intercalated $\mathrm{C}_{60}$ for $Q=$ \pm 1 and $Q= \pm 3$. The accuracy of the calculated DOS is about \pm 1 state per unit cell and $\mathrm{eV}$.

There is a clear trend that negatively charged systems have smaller DOS than positively charged systems. The small differences in shapes of the DOS of the $\mathrm{P} 1_{H T}$ and $\mathrm{P} \overline{1}_{L T}$ structures (Fig. П) become apparent in remarkable differences between DOS at the Fermi energy. The DOS at $E_{F}$ of the $\mathrm{P} 1_{H T}$ structures are for some charges larger and for other charges smaller than that of the $\mathrm{P}_{L T}$ structures. The discrepancies are up to 12 states per eV and unit cell and are primarily a result of different intermolecular distances (Table III) caused by differently oriented haloform and $\mathrm{C}_{60}$ molecules. Furthermore, due to narrow $\mathrm{VB}$ and $\mathrm{CB}$ peaks the DOS is sensitive with respect to the position of the Fermi energy.

However, at finite temperature the $\mathrm{P} 1_{H T}$ as well as the $\mathrm{P} \overline{1}_{L T}$ configuration can occur and the DOS at the Fermi energy for a particular charging would be an average of both [27]. Except for $Q=+1$ the averaged DOS is increasing as DOS(fcc $\mathrm{C}_{60}$ ) $<\operatorname{DOS}\left(\mathrm{C}_{60} \cdot 2 \mathrm{CHCl}_{3}\right)<\operatorname{DOS}\left(\mathrm{C}_{60} \cdot 2 \mathrm{CHBr}_{3}\right)$ (Table IV). But also for $Q=+1 \mathrm{C}_{60} \cdot 2 \mathrm{CHCl}_{3}$ has on average a smaller DOS than $\mathrm{C}_{60} \cdot 2 \mathrm{CHBr}_{3}$.

Table IV includes also the DOS at the Fermi energy of the hypothetical hexagonal lattice of pure $\mathrm{C}_{60}$ in the geometry of $\mathrm{P}_{H T} \mathrm{C}_{60} \cdot 2 \mathrm{CHCl}_{3}$ (see Section IV B 1). For all charges the calculations yields DOS that are very similar to that of $\mathrm{P}_{H T}$ $\mathrm{C}_{60} \cdot 2 \mathrm{CHCl}_{3}$. Hence, the orbitals of the $\mathrm{CHCl}_{3}$ molecules which interact with the $\pi$ system of the $\mathrm{C}_{60}$ subsystem have a negligibly influence on the DOS of the entire charged system.

\section{SUMMARY AND CONCLUSIONS}

Using density functional methods we have determined the electronic properties (band structure, partial and total density of states, charge distribution) of pure $\mathrm{C}_{60}$ and $\mathrm{C}_{60} \cdot 2 \mathrm{CHX}_{3}$ $(\mathrm{X}=\mathrm{Cl}, \mathrm{Br})$ after optimization of their atomic structures. The changes resulting from doping with one and three electrons/holes per unit cell have also been examined.

The calculations yielded for un-doped chloroform and bromoform intercalated $\mathrm{C}_{60}, \mathrm{C}_{60} \cdot 2 \mathrm{CHX}_{3}(\mathrm{X}=\mathrm{Cl}, \mathrm{Br})$ indirect gaps between the valence bands (VB) and conduction bands (CB) larger than $1 \mathrm{eV}$. Both $\mathrm{C}_{60} \cdot 2 \mathrm{CHCl}_{3}$ and $\mathrm{C}_{60} \cdot 2 \mathrm{CHBr}_{3}$ are narrow band materials, i.e. most of the electronic states are mainly localized on the molecules. The calculated width of the $\mathrm{VB}$ and $\mathrm{CB}$ are $0.4-0.6 \mathrm{eV}$ and $0.3-0.4 \mathrm{eV}$, respectively. The orbitals of the haloform molecules have a considerable overlap between the $\pi$ orbitals of the fullerene molecules and the $p$-type orbitals of halogen atoms significantly contribute to the $\mathrm{VB}$ and $\mathrm{CB}$ of $\mathrm{C}_{60} \cdot 2 \mathrm{CHX}_{3}$. Both compounds are mainly stabilized by dipole-induced dipole interactions rather than by van-der-Waals interactions. The intrinsically differently charged atoms of the haloform molecules cause a polarization of the fullerene molecules.

Doping with charge carriers turns the $\mathrm{C}_{60} \cdot 2 \mathrm{CHX}_{3}$ $(\mathrm{X}=\mathrm{Cl}, \mathrm{Br})$ to metals. As a result of the intermolecular overlap of the $\mathrm{CHX}_{3}$ and $\mathrm{C}_{60}$ orbitals, 10 to $20 \%$ of the charge of the doped systems is on the haloform molecules instead of being completely localized on the fullerene molecules. Charging with electrons leads to a shift of both $\mathrm{VB}$ and $\mathrm{CB}$ to higher energies whereas the doping with holes shift them to lower energies. The corresponding band widths undergo relatively small changes. At a charging of $Q=+3$ per $\mathrm{C}_{60} \cdot 2 \mathrm{CHX}_{3}$ the gap between the VB and the states just below the VB is significantly reduced. In the case of $\mathrm{C}_{60} \cdot 2 \mathrm{CHBr}_{3}$ the $\mathrm{VB}$ has even merged with states lower in energy. The calculated density of states at the Fermi energy for different chargings are clearly smaller for electron than for hole doping and are larger for $\mathrm{C}_{60} \cdot 2 \mathrm{CHBr}_{3}$ than for $\mathrm{C}_{60} \cdot 2 \mathrm{CHCl}_{3}$. Calculations on different crystal structures of $\mathrm{C}_{60} \cdot 2 \mathrm{CHCl}_{3}$ and $\mathrm{C}_{60} \cdot 2 \mathrm{CHBr}_{3}$ revealed that the density of states at the Fermi energy are sensitive to the orientation of the haloform and $\mathrm{C}_{60}$ molecules. At a given charge the differences between the various crystal structures are up to 12 states per eV and unit cell.

At a charging of $Q=+3$, which resembles the superconducting phase of pure $\mathrm{C}_{60}$ and $\mathrm{C}_{60} \cdot 2 \mathrm{CHX}_{3}(\mathrm{X}=\mathrm{Cl}, \mathrm{Br})$, we calculated DOS at the Fermi energy that increases as $\operatorname{DOS}\left(\mathrm{C}_{60}\right)<\operatorname{DOS}\left(\mathrm{C}_{60} \cdot 2 \mathrm{CHCl}_{3}\right)<\operatorname{DOS}\left(\mathrm{C}_{60} \cdot 2 \mathrm{CHBr}_{3}\right)$. On the other hand, the tight-binding calculations of Dinnebier et al. [3] yielded DOS that have the reverse order. This discrepancy is related to the different methods considered. The method used in the present work is more accurate than the tight-binding approach. Nevertheless, our calculations clearly supports the conclusion of Dinnebier et al. [3] that the DOS alone cannot account for the observed increase of $T_{c}$ upon $\mathrm{CHCl}_{3}$ intercalation and substitution of $\mathrm{Cl}$ by $\mathrm{Br}$. According to a different scenario proposed by Bill and Kresin [28] the increase of $T_{c}$ upon intercalation is caused by an additional contribution to the superconducting pairing interaction which 
comes from the coupling of charge carriers with the vibrational manifold of the intercalated molecules. The difference in vibrational spectra of $\mathrm{CHCl}_{3}$ and $\mathrm{CHBr}_{3}$ molecules [29] leads to a noticeable increase of $T_{c}$ upon $\mathrm{Cl} \rightarrow \mathrm{Br}$ substitution.

The present calculations have all been performed on a three-dimensional crystal in absence of an applied electric field. However, the presence of an electric field may lead to a re-orientation and polarization of the haloform and fullerene molecules. Such structural changes affect the electronic structure of the system and may influence vibronic couplings as well. It would be of interest to complement the study pre- sented in this article with calculations on $\mathrm{C}_{60} \cdot 2 \mathrm{CHX}_{3}$ $(\mathrm{X}=\mathrm{Cl}, \mathrm{Br})$ in an electric field. A similar problem has been examined for pure $\mathrm{C}_{60}$ [30].

\section{Acknowledgments}

We thank P.W. Stephen for sending the manuscript of Ref. [3] prior to publication.
[1] M. Jansen and G. Waidmann, Z. Anorg. Allg. Chem. 14, 621 (1995).

[2] C. Collins, J. Foulkes, A. D. Bond and J. Klinowski, Phys. Chem. Chem. Phys. 1, 5323 (1999).

[3] R. E. Dinnebier, O. Gunnarsson, H. Brumm, E. Koch, A. Huq, P. W. Stephens and M. Jansen, Science 296, 109 (2002).

[4] C. Collins, M. Duer and J. Klinowski, Chem. Phys. Lett. 321, 287 (2000).

[5] A. Hebard, Phys. Today 45, 26 (1992).

[6] O. Gunnarson, Rev. Mod. Phys. 69, 575 (1997).

[7] O. Gunnarson, E. Koch and R. Martin, in Pair Correlations in Many-Fermion Systems, edited by V. Z. Kresin (Plenum, New York, 1998), p. 155.

[8] J. H. Schön, C. Kloc and B. Batlogg, Nature 408, 549 (2000).

[9] A. Ramirez, personal communication.

[10] R. F. Service, Science 296, 1584 (2002).

[11] J. H. Schön, C. Kloc and B. Batlogg, Science 293, 2432 (2001).

[12] F. Meunier, J. P. Burger, G. Deutscher and E. Guyon , Phys. Lett. 26 A, 309 (1968).

[13] V. Z. Kresin, Phys. Lett. 49 A, 117 (1974).

[14] W. I. F. David, Appl. Radiat. Isotopes 46, 519 (1995).

[15] B. Delley, J. Chem. Phys. 92, 508 (1990).

[16] B. Delley, J. Chem. Phys. 113, 7756 (2000).

[17] A. D. Becke, J. Chem. Phys. 98, 5648 (1993).

[18] J. P. Perdew and Y. Wang, Phys. Rev. B 45, 13244 (1992).

[19] J. Andzelm, R. D. King-Smith and G. Fitzgerald, Chem. Phys. Lett. 335, 321 (2001).

[20] D. R. Lide, Handbook of Physics and Chemistry (CRC Press,
Boca Raton, 1998-1999), 79th ed.

[21] A. Ruiz, J. Bretón and J. M. Gomez Llorente, J. Chem. Phys. 114, 1272 (2001).

[22] M. J. Winter, WebElements ${ }^{\mathrm{TM}}$, the periodic table on the WWW, http://www.webelements.com (2002).

[23] R. W. Lof, M. A. van Veenendaal, B. Koopmans, H. T. Jonkman and G. A. Sawatzky, Phys. Rev. Lett. 68, 3924 (1992).

[24] J. C. Slater, Adv. Quantum Chem. 6, 1 (1972).

[25] D. A. Liberman, Phys. Rev. B 62, 6851 (1999).

[26] F. L. Hirshfeld, Theor. Chim. Acta 44, 129 (1977). The charge of an atom $N$ is calculated as $q(N)=\int \rho_{d}(r) W_{N}(r) d r$, where $W_{N}(r)=\rho_{N}\left(r-R_{N}\right)\left[\sum_{M} \rho_{M}\left(r-R_{M}\right)\right]^{-1}$ is the weight and $M$ is the sum index over all atoms. The deformation charge density, $\rho_{d}$, is the difference between the charge density of the system and the density of the separated atoms and is given by $\rho_{d}(r)=$ $\rho(r)-\sum_{M} \rho_{M}\left(r-R_{M}\right)$.

[27] At a temperature of $T=100 \mathrm{~K}$ the Boltzmann statistic yields for the ratio of the occurrence of the $\mathrm{P}_{H T}$ and the $\mathrm{P} \overline{1}_{L T}$ configurations of $\mathrm{C}_{60} \cdot 2 \mathrm{CHCl}_{3}$ almost one when the energy difference between both configuration is $28 \mathrm{~kJ} \cdot \mathrm{mol}^{-1}$ (see Table II).

[28] A. Bill and V. Z. Kresin, Eur. Phys. J. B 26, 3 (2002).

[29] G. Herzberg, Molecular Spectra and Molecular Structure. II. Infrared and Raman Spectra of Polyatomic Molecules (D. Van Nostrad, Princeton, 1964).

[30] S. Wehrli, D. Poilblanc and T. Rice, Eur. Phys. J. B 23, 345 (2001). 